\title{
Exposure to boat noise in the field yields minimal stress response in wild reef fish
}

\author{
E. Staaterman ${ }^{1,2,3, *}$, A. J. Gallagher ${ }^{2,3}$, P. E. Holder ${ }^{4}$, C. H. Reid ${ }^{4}$, A. H. Altieri ${ }^{2,5}$, \\ M. B. Ogburn ${ }^{1}$, J. L. Rummer ${ }^{6}$, S. J. Cooke ${ }^{4}$ \\ ${ }^{1}$ Smithsonian Environmental Research Center, 647 Contees Wharf Road, Edgewater, MD 21037, USA \\ ${ }^{2}$ Smithsonian Tropical Research Institute, Bocas del Toro, Panama \\ ${ }^{3}$ Beneath the Waves, Herndon, VA 20172, USA \\ ${ }^{4}$ Fish Ecology and Conservation Physiology Laboratory, Department of Biology and Institute of Environmental \\ and Interdisciplinary Science, Carleton University, Ottawa, ON K1S 5B6, Canada \\ ${ }^{5}$ Department of Environmental Engineering Sciences, University of Florida, FL 32611, USA \\ ${ }^{6}$ ARC Centre of Excellence for Coral Reef Studies, James Cook University, Townsville, QLD 4811, Australia
}

\begin{abstract}
Aquatic anthropogenic noise is on the rise, with growing concern about its impact on species that are sensitive to low-frequency sounds (e.g. most fish and invertebrates). We investigated whether the reef fish Halichoeres bivittatus living in both noisy and quiet areas had differing levels of baseline stress (measured as whole-body cortisol) and whether they would exhibit a physiological stress response when exposed to boat noise playbacks. While the playback experiments significantly increased cortisol levels in fish from our experiment compared to baseline levels, there were minimal pairwise differences across treatments and no difference in baseline stress for fish living in noisy vs. quiet areas. These results may be explained by low overall auditory sensitivity, habituation to a fairly noisy environment (due to biological sounds), or that boat noise simply may not represent an immediate threat to survival in this species. These findings contrast recent studies that have shown elevated stress responses in fishes when exposed to boat noise and highlights that inter-specific differences must be considered when evaluating potential impacts of anthropogenic noise on marine life.
\end{abstract}

KEY WORDS: Anthropogenic noise $\cdot$ Reef fish $\cdot$ Stress

\section{INTRODUCTION}

As human activity in the oceans has increased, so have levels of anthropogenic noise. Noise is one of many stressors that marine species are facing in the oceans of today, yet understanding its potential consequences on wildlife is challenging due to the complex interactions of physics, biology, physiology, and animal behavior. Initially, most concerns about anthropogenic noise in marine environments focused on acute impacts (e.g. physical injury and hearing loss) from the most intense sound sources (e.g. explo-

*Corresponding author: e.staaterman@gmail.com sions, navy sonars, and seismic airguns), with a particular emphasis on marine mammals because of their complex vocalizations and hearing systems (Parsons et al. 2008, Finneran 2015, Williams et al. 2015). As the field has progressed, however, greater attention has been directed toward lower trophic level species, as investigators have realized that they, too, are sensitive to sound and could be impacted by noise (Slabbekoorn et al. 2010, De Soto 2016, Hawkins \& Popper 2017, Cox et al. 2018). In addition, there is growing evidence of non-injurious effects, such as changes in behavior, increases in physiological stress,

(C) The authors 2020. Open Access under Creative Commons by Attribution Licence. Use, distribution and reproduction are unrestricted. Authors and original publication must be credited. 
or interference with communication systems (Wright et al. 2007, Kight \& Swaddle 2011, Erbe et al. 2016). These impacts may be more long-term and more widespread, as lower sound levels are required to elicit such responses.

Noise from vessel traffic is an example of a stressor that is both chronic and widespread. The cavitation of boat propellers creates a continuous, low-frequency sound that is now nearly ubiquitous in the ocean and has steadily increased with the growth of the global economy (Hildebrand 2009, Andrew et al. 2011, Frisk 2012). Automatic identification systems (AIS) on commercial ships have proven useful for quantifying and predicting ocean sound levels (Hatch et al. 2008, Roul et al. 2019) as well as potential impacts on marine mammals (Erbe et al. 2014, 2019, Merchant et al. 2014). Although smaller boats do not have this technology, some studies have demonstrated that noise from small vessels makes a significant contribution to coastal soundscapes and may affect behavior of wildlife in these areas (Codarin et al. 2009, Kaplan \& Mooney 2015, Wladichuk et al. 2018). Considering how frequent such boat traffic is in some coastal areas, this is an important area of ongoing research. Furthermore, because small boats produce sounds that overlap in frequency with the hearing range of most fishes and invertebrates (typically $<1$ $\mathrm{kHz}$ ), boat noise may be a significant stressor for these species (Popper \& Hastings 2009). Studies on fishes have shown that responses vary depending on engine noise type, field versus laboratory settings, and within and between taxonomic groups (Normandeau Associates 2012, Hawkins \& Popper 2017, JainSchlaepfer et al. 2018).

Indeed, previous research on the effects of boat noise on fishes has yielded variable results: laboratory studies tend to focus on physiological endpoints, while field studies tend to investigate behavioral responses. Codarin et al. (2009) found that, when exposed to boat noise in the laboratory, hearing thresholds of 3 Mediterranean fishes increased. Scholik \& Yan (2002) found a similar result in fathead minnows. A tank study on 3 freshwater fishes resulted in significant increases in glucocorticoid hormones upon exposure to ship noise for just $30 \mathrm{~min}$ (Wysocki et al. 2006), and juvenile kelp bass reacted similarly in response to intermittent (but not constant) boat noise (Nichols et al. 2015). In another tank study, potential longer-term impacts of noise exposure were explored: after $10 \mathrm{~d}$ of noise exposure, gilthead seabream showed significant increases in several blood parameters including adrenocorticotropic hormone, cortisol, glucose, lactate, and hematocrit (Celi et al. 2016).
Heart rates have also been used as a measure of stress: Graham \& Cooke (2008) exposed largemouth bass to real operational engine motors inside a tank and saw that heart rates increased the most in response to motorboat engines compared to quieter trolling engines or non-motorized paddle strokes; a similar result was found in embryonic damselfish (Jain-Schlaepfer et al. 2018).

Several field studies have also shown that fishes change their behavior in response to boat noise. For example, a brooding damselfish, when subjected to playbacks of boat noise in the field, changed its typical brooding behaviors (Nedelec et al. 2017), and a different damselfish species showed a diminished reaction to predators after exposure to motorboat noise (Simpson et al. 2016). In largemouth bass, nestguarding males slightly altered natural parental care behaviors when exposed to noise, but only when their offspring were a certain age (Maxwell et al. 2018). These studies suggest that the presence of noise either decreased vigilance or masked the ability of these fishes to detect potential threats. Swimming behaviors can also be affected by noise: noise from passenger ferries and small boats disrupts schooling in captive bluefin tuna (Sara et al. 2007), and Norwegian herring seem to flee in response to an approaching vessel (Vabo et al. 2002). Similarly, Schwarz \& Greer (1984) showed that Pacific herring exhibit avoidance responses when exposed to sounds meant to simulate approaching vessels. Taken together, these studies indicate that fishes respond to the presence of real boats, as well as the sounds of boats in both laboratory and field environments. And while behavioral responses are important metrics to track, there has been a noticeable lack of focus on stress physiology in field studies; such work is important because primary responses to stressors can underlie whole-body responses that are typically observed as changes in behavior (Barton 2002).

One particular topic that has not been sufficiently investigated is whether fishes habituate to high levels of background noise. Chronic stress, which can result in elevated glucocorticoid levels for extended periods of time, can have significant metabolic and fitness-level consequences (Barton 2002). One study found that a coral reef fish initially hid behind rocks when encountering boat noise, but was less likely to react this way after $1 \mathrm{wk}$ of noise exposure, indicating that its initial response was dampened (Nedelec et al. 2016). When cortisol levels were tested after $1 \mathrm{wk}$, they were no different from those of controls, providing no evidence of chronic stress due to repeated noise exposure (Nedelec et al. 2016). Simi- 
larly, sounds of pile-driving and seismic airguns initially triggered a stress response in European seabass, but after $12 \mathrm{wk}$ of exposure, this response was diminished; the exposed fish showed no evidence of chronic stress (Radford et al. 2016). Given the relatively few studies on this subject, it is unclear whether fish living in high-noise areas become habituated or sensitized to noise. It is also unclear whether populations might diverge in their responses. All of this could depend on background noise conditions of their respective habitats. In other words, do fishes living in areas with chronic noise experience chronic stress, and do they still exhibit a stress response when exposed to acute noise events?

To explore these questions, we collected baseline physiological data from populations of a common Caribbean reef fish, the slippery dick wrasse Halichoeres bivittatus that lives in areas with varying degrees of boat activity. We also measured the physiological stress responses in fish from these different populations following a series of boat noise playback experiments. We addressed 3 primary questions: (1) Are there differences in baseline stress biomarkers for populations from noisy vs. quiet areas? (2) Does $H$. bivittatus exhibit a change in stress markers when experimentally exposed to boat noise? (3) Are there variations in the stress response among populations from noisy vs. quiet sites upon exposure to boat noise playbacks? We discuss our findings as they relate to the growing field of research seeking to evaluate the effects of anthropogenic noise on aquatic ecosystems.

\section{MATERIALS AND METHODS}

\subsection{Collection sites, baseline acoustic recordings, and whole-body cortisol methods}

Our work was conducted on the Caribbean coast of Panama in the Bocas del Toro region $\left(9.33^{\circ} \mathrm{N}\right.$, $82.25^{\circ} \mathrm{W}$ ), where Halichoeres bivittatus is highly abundant. We identified 2 sites within the region that had substantially different levels of boat traffic; acoustic recordings and fish collections were conducted at these 2 sites. The 'noisy' site, Hospital Point, is a hardbottom habitat with scattered corals and reefassociated fauna that lies directly underneath a busy channel, where passenger ferries and water taxis frequently pass at high speeds (Fig. 1A). The 'quiet' site, STRI Point, is a protected seagrass bed fringed by mangroves and small coral reefs, near the Smithsonian Tropical Research Institute's field station (STRI; Fig. 1A). Typical boat traffic in this area is lim- ited to small boats moving at slow speeds as they come and go from the research station. We deployed passive acoustic recorders (DSG, Loggerhead Instruments; $20 \mathrm{kHz}$ sampling rate) at each of these sites for several days in order to quantify boat activity and ambient sound levels. A full analysis of soundscapes around different parts of the Archipelago can be found in Staaterman et al. (2017). Briefly, our recordings confirmed that the acoustic conditions (below 1 $\mathrm{kHz}$, the frequency range that most fish can hear) of these 2 areas differ by up to $10 \mathrm{~dB}$ during daytime hours (Fig. 1B). By manually scanning the recordings, we found that an average of approximately 30 boats $\mathrm{h}^{-1}$ (between 07:00 and 19:00 h) pass nearby at Hospital Point, compared to 10 boats $\mathrm{h}^{-1}$ at STRI Point. Sound levels during a representative $24 \mathrm{~h}$ window are depicted in Fig. 1B.

To understand whether there were differences in baseline stress biomarkers for $H$. bivittatus individuals living at the noisy and quiet sites, we measured whole-body cortisol and blood glucose (2 common stress biomarkers in fish; Sopinka et al. 2016). Over the course of $5 \mathrm{~d}$ (18-22 January 2016), 20-30 animals were collected at $\sim 400 \mathrm{~m}^{2}$ areas at each of the 2 sites. Individual fish were captured using a lift-net baited with crushed sea urchins. Upon capture, animals were immediately sacrificed via cerebral percussion, as it was the fastest and most efficient means possible (IACUC permit 2016-0101-2019-A1). An incision was made near the heart to withdraw a fresh blood sample $(0.1 \mathrm{ml})$, which was then analyzed on a test strip for glucose using a portable glucose meter (ACCU-CHEK glucose meter; Roche Diagnostics) previously validated for use in fish (Stoot et al. 2014). The carcasses were measured for total length and frozen immediately for later whole-body cortisol processing. The total time for capture, euthanasia, and sampling prior to being frozen was less than $3 \mathrm{~min}$ (Lawrence et al. 2018). The goal of our rapid processing was to characterize the condition of the fish prior to capture without data being unduly influenced by handling.

To obtain whole-body cortisol levels for each fish, we generally followed the procedures outlined in Sopinka et al. (2014), Jeffrey \& Gilmour (2016), and Redfern et al. (2017). Individual fish were removed from their respective frozen bags and the proximal portion of each fish (anterior of midway between the operculum and pelvic girdle) was removed using a serrated duct knife. The fish tissue was ground into a very fine homogeneous powder with a mortar and pestle, then transferred into $5 \mathrm{ml}$ bullet tubes. The tubes with the ground fish tissue were returned to 

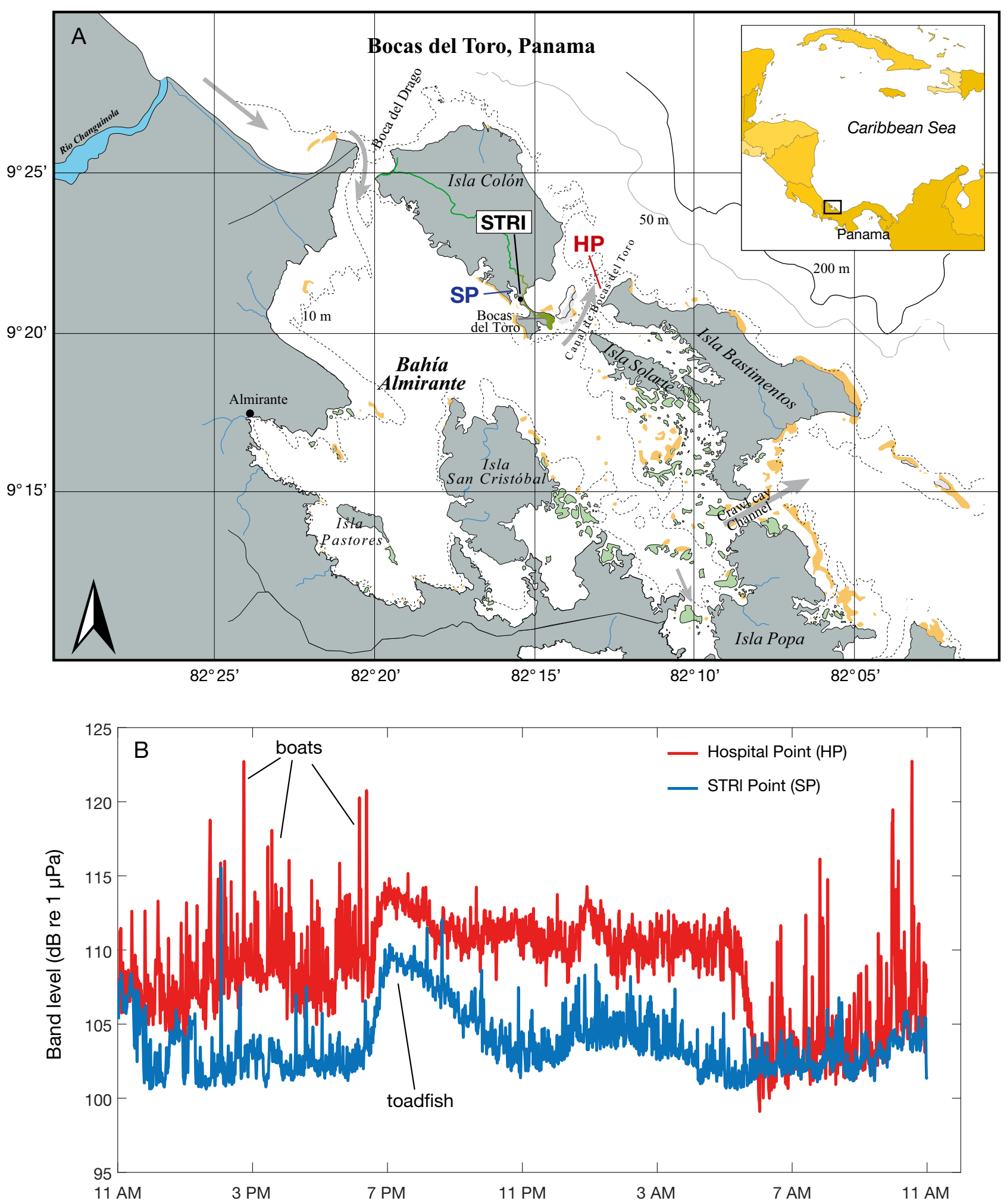

Fig. 1. (A) Study site within the Bocas del Toro Archipelago on the Caribbean coast of Panama; Halichoeres bivittatus specimens were collected at Hospital Point (HP), a hardbottom area with frequent vessel traffic, and STRI Point (SP), a quiet, protected bay with seagrass and patchy corals. Playback experiments took place near SP. (B) Representative $24 \mathrm{~h}$ acoustic recording at the 2 sites showing different acoustic conditions within the frequency band of $1-1000 \mathrm{~Hz}$. The frequent passage of boats at HP (average: 30 boats $\mathrm{h}^{-1}$ during the day) can be seen as sharp peaks. At both sites, low-frequency sound levels increased at night due to chorusing toadfish (Staaterman et al. 2018). STRI: Smithsonian Tropical Research Institute's field station 
the bag with the rest of the carcass and stored at $-80^{\circ} \mathrm{C}$ until the extraction process. Throughout the process, the knife, scoopula, mortar, and pestle were cooled with liquid nitrogen and cleaned between samples to prevent cross-contamination. Next, the pulverized frozen tissue was decanted into a small test tube; an extraction buffer (Neogen Cortisol Kits, Neogen) was added (730 $\mu$ l of buffer $\mathrm{g}^{-1}$ of tissue). Samples were then homogenized on ice using sonication, and diethyl ether was added to the sample (2.5 $\mathrm{ml} \mathrm{g}^{-1}$ of tissue). The sample was vortexed and placed in a refrigerator at $4^{\circ} \mathrm{C}$ for $60 \mathrm{~min}$. Next, samples were centrifuged at $3000 \times g$ for $5 \mathrm{~min}$ at $4^{\circ} \mathrm{C}$, then flash frozen at $-80^{\circ} \mathrm{C}$ for $30 \mathrm{~min}$. Supernatant liquid was pipetted into a separate tube, and remnants were left to thaw before 2 further repetitions of vortexing and centrifuging. Remnant supernatant liquid in each tube was evaporated using a gentle stream of air, leaving only the cortisol-containing residue. Samples were reconstituted using Neogen extraction buffer $\left(2 \mathrm{ml} \mathrm{g}^{-1}\right.$ of tissue; Neogen Cortisol Kits). Samples were used at full strength for enzymelinked immunosorbent assay (ELISA) quantification. ELISA quantification combines sample cortisol with a cortisol conjugate, both of which compete for the same antibody-dependent binding sites on a single plate. As only the conjugate reflects light, more color corresponds with less analyte. Sample absorbency $(\lambda=450 \mathrm{~nm})$ is then compared to 8 in-plate standards to quantify cortisol concentration. It was difficult to obtain adequate blood volumes for glucose readings during collection of our baseline samples, so the sample sizes for this component of our work were too low for statistical analyses.

\subsection{In situ acoustic playback experiment}

To test whether $H$. bivittatus exhibited a stress response when exposed to boat noise, we collected fish at each of the 2 sites and conducted an in situ playback experiment. We collected a total of 40 fish site si $^{-1}$ over a span of 9 d (12-20 February 2016), with a maximum of 10 ind. $\mathrm{d}^{-1}$ due to limitations of our experimental arena. Fish were collected using the same lift-net as described above. Upon capture, fish were immediately transferred to a cooler filled with seawater and transported back to the experimental arena: a shallow seagrass bed (2 $\mathrm{m}$ water depth) near STRI Point, where $H$. bivittatus are commonly observed. We crafted cylindrical mesh cages $(30 \mathrm{~cm}$ length, $10 \mathrm{~cm}$ diameter, $5 \mathrm{~mm}$ mesh size) that were placed $50 \mathrm{~cm}$ apart along horizontal PVC frames (Fig. 2). Each PVC frame held up to 5 cages, and the 2 frames were $4 \mathrm{~m}$ apart with the speaker located in the middle. All $H$. bivittatus individuals were placed one each into the 5 mesh cages on one side of the arena. After a minimum of $1 \mathrm{~h}$ of acclimation, they were either subjected to the 'noisy' or 'control' treatment.

For the noisy treatment, playbacks were generated from the $24 \mathrm{~h}$ recordings from Hospital Point. Using Raven Pro 1.4 (Cornell University), we created two 60 min playback files consisting of approximately 30 intermittent boat pass-overs (typical for this location), randomly spaced in time. Two boat noise playback files were created to avoid pseudo-
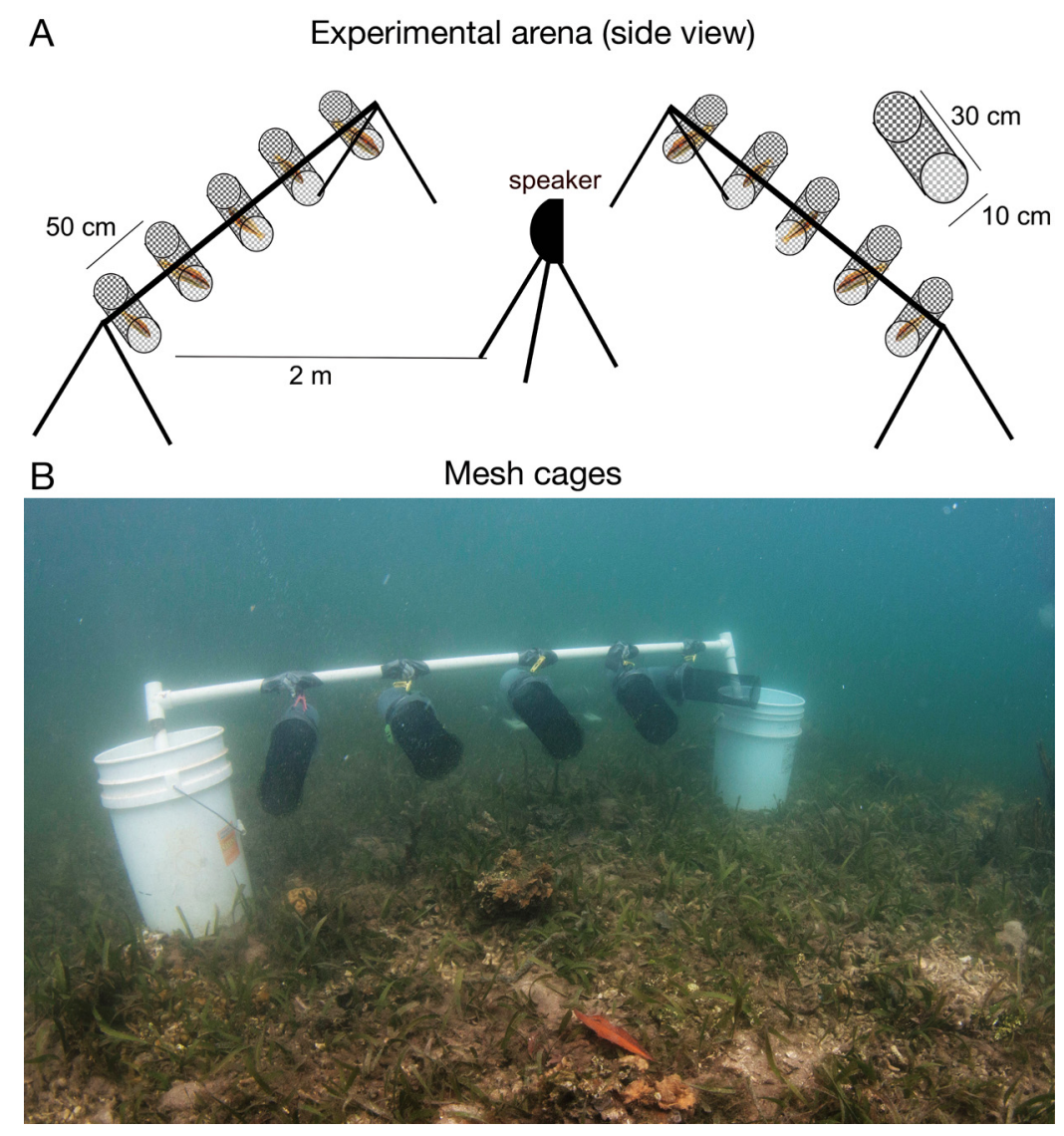

Fig. 2. (A) Diagram of the experimental arena, with the 2 rows of small mesh cages and the speaker in the middle; (B) photo from behind one of the rows of cages. The speaker (not visible) is on the other side of the setup 
replication and were randomly chosen throughout all experiments. We recorded the natural habitat sounds in our experimental arena and found that they were equivalent to those measured at the quiet site; thus, there was no need to play back additional sounds from the speaker during the control treatment (Fig. 3).

To match the boat playbacks to real boat sounds recorded in situ, we calibrated our underwater speaker system. The underwater speaker (Aquasonic AQ339, Clark Synthesis) was powered by an amplifier (SX220.2, Cerwin-Vega) and $12 \mathrm{~V}$ marine battery. The passive acoustic recorders measured the received levels at the location of the fish during the playbacks. Using the RMS sound pressure level of a specific boat pass-over as recorded at Hospital Point (125 dB re $1 \mu \mathrm{Pa}$ ) as a target, we adjusted the gain on the amplifier so that received levels at the site of the fish were within $2 \mathrm{~dB}$ of this target during the same boat pass-over. Some spectral distortion due to the speakers was unavoidable (Fig. 3), however. Sounds were high-pass filtered at $3 \mathrm{kHz}$ prior to playback to avoid high-frequency artefacts from the speakers.

After the $1 \mathrm{~h}$ playback period, the fish were sacrificed and processed using the same protocol as described above for baseline stress markers and then im- mediately frozen for future cortisol assays. On any given day, we were only able to conduct one noisy and one quiet treatment (i.e. we collected and used a maximum of 10 ind.), and between days we alternated the order of the 2 treatments and the frames used for each.

The effects of experimental handling stress, collection site, and noise treatment on fish cortisol levels were evaluated by comparing the baseline, control playback, and noisy playback treatments between sites using ANCOVA. Prior to analysis, cortisol data were square root transformed to meet assumptions of normality. A 2-way ANCOVA was conducted in MATLAB R2017B (MathWorks) with site and treatment as independent variables and body length as the covariate. Pairwise multiple comparisons were conducted to identify which treatments were significantly different.

To examine potential differences in glucose levels across playback treatments, we first used a linear regression to determine whether there was a significant relationship between body length and glucose. We found no relationship, so we used ANOVA to look for differences in mean glucose levels between the 4 groups described above. Since the glucose data did not meet assumptions of normality, the data were first square root transformed.

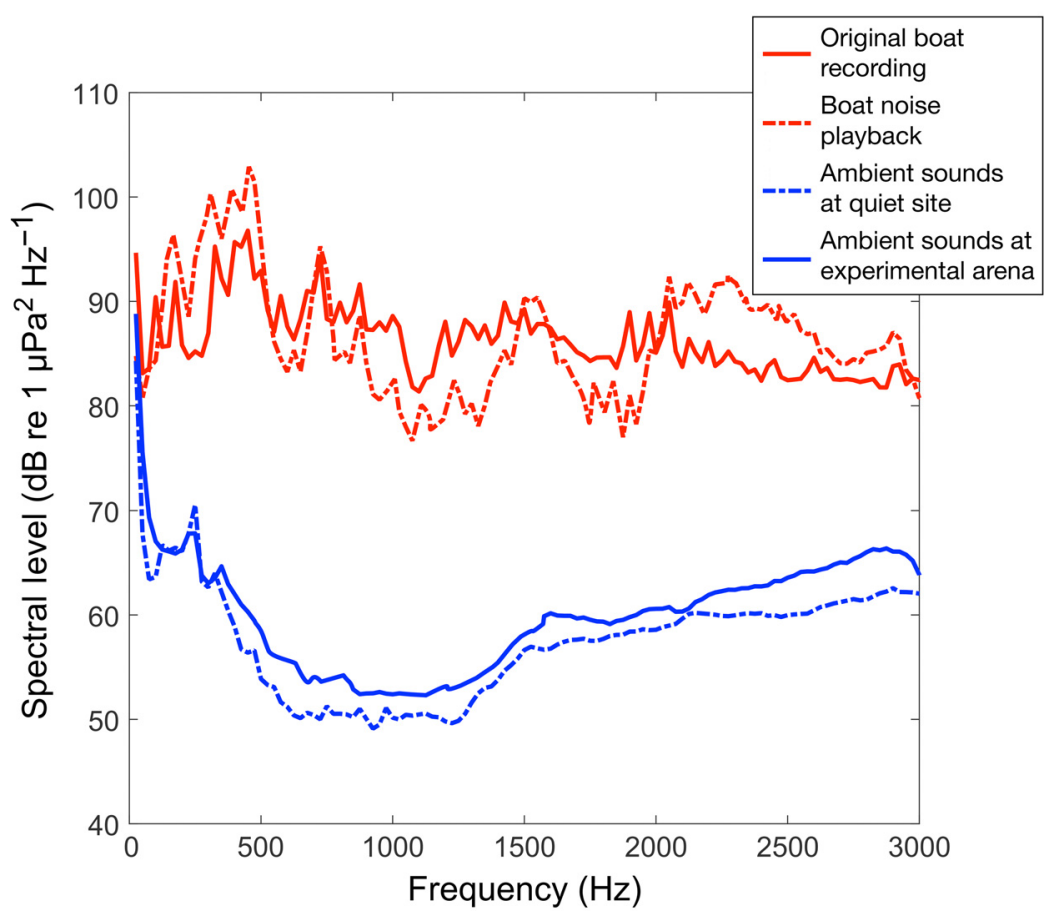

Fig. 3. Underwater speakers broadcast boat sounds (spectrum of representative boat pass shown as dashed red line) from recordings made at the noisy site (same boat pass; solid red line) in the in situ experiment. Because ambient sounds at the experimental arena (solid blue line) were similar to the quiet site (dashed blue line), no playbacks occurred during the control treatment

\section{RESULTS}

Fish included in the playback experiments had higher whole-body cortisol levels than those sacrificed immediately to measure baseline stress levels, but differences among sites and treatments were minimal. The mean $( \pm \mathrm{SE})$ whole-body cortisol level varied from $1.17 \pm 0.22 \mathrm{ng} \mathrm{g}^{-1}$ for baseline fish collected at STRI Point to $4.80 \pm 0.39 \mathrm{ng}$ $\mathrm{g}^{-1}$ for fish collected at Hospital Point and exposed to the noisy treatment (Table 1). There was a negative linear relationship between body length and cortisol levels, and there were significant effects of site and fish body length (Table 2). Post hoc multiple comparisons tests (Table A1 in the Appendix) revealed that fish from STRI Point were smaller than those from Hospital Point, but there were no differences in size among treatments. Baseline cortisol levels did not differ between sites. Fish exposed to experimental treat- 
Table 1. Sample sizes, mean body length, whole-body cortisol, and glucose levels for Halichoeres bivittatus used in both the baseline study and the in situ experimental portion of the study. Values are reported as means \pm SE. We were not able to obtain glucose readings for all fish, so the sample sizes for glucose data are reported separately in the last column

\begin{tabular}{|llccccc|}
\hline Experiment & $\begin{array}{l}\text { Collection } \\
\text { site }\end{array}$ & $\begin{array}{c}\text { Noise } \\
\text { treatment }\end{array}$ & $\begin{array}{c}\text { Sample } \\
\text { size }\end{array}$ & $\begin{array}{c}\text { Mean body } \\
\text { length }(\mathrm{cm})\end{array}$ & $\begin{array}{c}\text { Mean whole-body } \\
\text { cortisol }\left(\mathrm{ng} \mathrm{g}^{-1}\right)\end{array}$ & $\begin{array}{c}\text { Mean glucose } \\
\left(\mathrm{mmol} \mathrm{l}^{-1}\right)\end{array}$ \\
\hline Baseline & STRI Point & - & 31 & $6.17 \pm 0.53$ & $1.17 \pm 0.22$ & $3.9(\mathrm{n}=1)$ \\
Baseline & Hospital Point & - & 19 & $8.19 \pm 0.58$ & $1.28 \pm 0.29$ & $4.4 \pm 0.6(\mathrm{n}=16)$ \\
In situ playback & STRI Point & Control & 19 & $6.70 \pm 0.38$ & $4.53 \pm 0.72$ & $4.17 \pm 0.37(\mathrm{n}=14)$ \\
In situ playback & STRI Point & Noisy & 21 & $7.21 \pm 0.39$ & $3.87 \pm 0.59$ & $4.52 \pm 0.55(\mathrm{n}=20)$ \\
In situ playback & Hospital Point & Control & 17 & $7.93 \pm 0.46$ & $3.97 \pm 0.68$ & $3.25 \pm 0.23(\mathrm{n}=15)$ \\
In situ playback & Hospital Point & Noisy & 19 & $9.11 \pm 0.47$ & $4.80 \pm 0.39$ & $3.97 \pm 0.29(\mathrm{n}=18)$ \\
\hline
\end{tabular}

Table 2. In situ playback experiment: results of the 2-way ANCOVA for whole-body cortisol levels in Halichoeres bivittatus, with site and treatment as independent variables and length as a covariate

\begin{tabular}{|lccccc|}
\hline Source & df & SS & MS & $F$ & Prob $>F$ \\
\hline Treatment & 1 & 0.7951 & 0.79508 & 5.71 & $\mathbf{0 . 0 1 8 4}$ \\
Site & 2 & 14.8229 & 7.41146 & 53.23 & $<\mathbf{0 . 0 0 1}$ \\
Length & 1 & 3.0505 & 3.05052 & 21.91 & $<\mathbf{0 . 0 0 1}$ \\
Error & 124 & 17.2641 & 0.13923 & & \\
Total & 128 & 35.9212 & & & \\
\hline
\end{tabular}

ments had significantly higher cortisol levels than baseline fish, with fish in the Hospital Point noisy treatment having slightly, but significantly higher values than fish in the Hospital Point control treatment and both STRI Point treatments.

In contrast, there was no relationship between body length and glucose levels $\left(F=0.69, \mathrm{df}=69, \mathrm{R}^{2}=\right.$ $0.01, p=0.41$ ). There was also no difference in the mean glucose levels across the 4 groups $(F=1.01$, $\mathrm{df}=3, \mathrm{p}=0.39$ ).

\section{DISCUSSION}

While boat noise playback experiments significantly increased cortisol levels in Halichoeres bivittatus from our experiment compared to baseline levels, there were minimal pairwise differences across treatments and no difference in baseline stress for fish living in noisy vs. quiet areas. The one difference - fish from the noisy site had slightly but significantly higher cortisol levels in response to the noisy vs. control treatments, whereas no difference was observed for fish from the quiet site - was potentially confounded by fish from the noisy site being significantly larger on average than those from the quiet site. This result of minimal differences was somewhat surprising, considering the recent studies that have shown a heightened stress response in fishes exposed to boat noise (e.g. Wysocki et al. 2006, Nichols et al. 2015, Celi et al. 2016). Thus far, the majority of studies examining physiological responses of fishes to boat noise have been conducted in laboratory settings, rather than the field. Playback work in the laboratory is inherently flawed, as the physical boundaries of tanks can distort acoustic frequencies and present abnormal cues to the study subjects (Akamatsu et al. 2002). Because most fish are sensitive to particle motion, which is the dominant acoustic cue close to a sound source, when very close to the speaker they may have perceived high levels of particle motion and/or abnormal directional cues (Popper \& Hawkins 2018, 2019). In addition, 3 laboratory studies (Wysocki et al. 2006, Nichols et al. 2015, Celi et al. 2016) used sound pressure levels that were 10-30 dB above those used in our experiments (within an equivalent frequency range), so it is not surprising that they may have seen a more pronounced response. The playback of a boat at $20 \mathrm{~m}$ distance in Nichols et al. (2015) most closely approximated our playback levels and, interestingly, this study showed a negative correlation between playback levels and cortisol concentrations. Therefore, it is likely that both the proximity and amplitude of the sounds received will influence the degree of response observed. Future experiments should further explore this relationship.

We calibrated our overall playback amplitudes to match recordings from the reef, where real boats passed anywhere from 5-50 m from the recorder. During the experiments, fish subjects were at least $2 \mathrm{~m}$ from the speaker and, with no reverberant boundaries nearby, the sound field they received during the intermittent boat sounds would have resembled that of a real boat passing several meters away. Therefore, it is reasonable to assume that the received levels in the experiment matched what $H$. bivittatus 
would encounter in its natural habitat. However, it should be acknowledged that the underwater speaker was a stationary monopole source, and that the directionality of particle motion created by a real, moving boat would be quite different. Not much is known about hearing capabilities of wrasses in general (Tavolga \& Wodinsky 1963, Boyle \& Cox 2009) and there is no published audiogram for $H$. bivittatus so it is difficult to know how well our specimens were able to detect the playback sounds. The fact that we failed to observe a strong stress response in animals exposed to boat noise may be explained by poor auditory sensitivity - either the particle motion field that was received at $2 \mathrm{~m}$ distance from the speaker was too faint to be detected above ambient levels, or that it simulated a sound that was non-moving so it did not represent a true threat. It also could be that since this species is accustomed to fairly high levels of natural sounds, it was simply unphased by the additional noise from the boats. Future field-based studies of this nature should include a particle motion sensor at the location of the specimens so the actual received acoustic cues can be quantified, and other investigators should consider having real boats drive by the animals, rather than a stationary speaker. Finally, additional work on auditory sensitivity in wrasses would shed further light on these results.

We hypothesized that $H$. bivittatus that lived in noisy habitats would have different levels of baseline stress, and that fish from these areas would exhibit a different response to boat noise compared to animals living under quiet conditions. Our results support neither of these hypotheses. While fish from the noisy site appeared to respond to the noisy playback treatment with significantly higher cortisol values than the control treatment, we can not determine whether their responses were different from fish from the quiet site due to significant differences in fish body length between sites. We found no evidence of 'chronic' stress (i.e. no difference in whole-body cortisol in baseline fish) for fish from the noisy area compared to fish living in quiet areas, although we acknowledge the limit in replication ( $\mathrm{n}=1$ for each site type) and the fact that we only measured glucocorticoids as an endpoint. Nonetheless, our results are consistent with previous work in fishes. Weeks of boat noise exposure had no effect on plasma cortisol concentrations in damselfish (Nedelec et al. 2016), long-term exposure to white noise had no effect on cortisol in goldfish (Smith 2004), and long-term exposure to pile-driving noise did not affect ventilation, growth, or mortality rates in European sea bass (Radford et al. 2016). Our findings suggest that popula- tions of $H$. bivittatus exhibit no evidence of chronic stress, based on our assessment of baseline cortisol levels.

We observed a significant negative correlation between body size and whole-body cortisol (Fig. A1 in the Appendix) but no relationship with plasma glucose. We intended to use plasma cortisol as an indicator of stress, but we quickly discovered that, due to its small size, $H$. bivittatus did not appear to have enough blood to make this method feasible. Instead, we had to use lethal sampling and obtain whole-body cortisol measurements, as in Ramsay et al. (2006). Whole-body cortisol levels have been used to assess the stress response of developing salmonids and sturgeon because blood volumes are insufficient to provide measurements of circulating cortisol (de Jesus \& Hirano 1992, Simontacchi et al. 2009). Similarly, whole-body corticosteroids have been measured in smaller adult fishes such as three-spined sticklebacks (Pottinger et al. 2002). In the present study, cortisol measurements were standardized per mass of tissue, so the inverse relationship with size was not an artefact of sampling but instead relates to fish life history. The fact that smaller fish had higher levels of whole-body cortisol suggests that these individuals may be more sensitive to stressors such as noise or handling stress. Our study did not resolve the role of sex in whole-body cortisol levels. $H$. bivittatus are protogynous hermaphrodites, and the exact size at which they transition from female to male may vary across populations (Robertson et al. 1978). However, using a general assumption that they change sex at $80 \%$ of maximum total body length (Allsop \& West 2003), with the maximum length of $35 \mathrm{~cm}$ (Froese \& Pauly 2019), this would occur at $28 \mathrm{~cm}$. All of our fish were $<15 \mathrm{~cm}$, so it is reasonable to assume that they were either juveniles or females. Future studies could specifically target large males (based on coloration) to further examine the potential relationship between reproductive state and cortisol response.

We recognize that we did not obtain a positive control in this study which would improve the tractability of boat noise as a stressor and the validity of wholebody cortisol as a useful biomarker across treatments. However, cortisol is indeed the universal biomarker for evaluating stress in wild fish (Barton 2002), and conducting numerous treatments, beyond exposing fish to boat noise, was beyond the scope of the study. While there is a general trend in the literature towards observing positive physiological and behavioral effects of boat noise in temperate and tropical fish, those results have largely been obtained 
in laboratory settings (Cox et al. 2018). Our findings suggest that null results or subtle effects (e.g. Maxwell et al. 2018) may be more common in field-based studies than previously thought. We also learned that these more subtle effects can be masked by experimental procedures involving handling.

\section{CONCLUSIONS}

Taken together, our results suggest that boat noise does not represent a significant stressor for Halichoeres bivittatus. Despite living in very different acoustic conditions (Fig. 1B), fish from the 2 sites exhibited no differences in baseline (i.e. chronic) stress. When exposed to boat noise at similar levels that they would experience in these 2 habitats, fish from the quiet site showed no differences and fish from the noisy site showed slightly higher cortisol levels, although direct comparisons between sites were confounded by differences in fish body length. The biggest effects observed related to body size and experimental handling. Smaller fish and all fish that were held in the experimental cages exhibited a heightened stress response. This result suggests that being handled represents a proximal stressor, perhaps simulating a predation event, to which small fish are particularly sensitive. Boat noise-especially if perceived as coming from a distant boat-may represent a more benign threat that does not pose an immediate risk to survival. To our knowledge, this is the first study to demonstrate that wild reef fishes may be somewhat resilient or indifferent to the presence of boat noise. This work stands in contrast to the majority of recent studies on fish and noise, underscoring the need to consider species-specificity when assessing the overall impacts of anthropogenic noise on marine life.

Acknowledgements. This work was conducted under collection permit SE/AP-2-16 and STRI IACUC permit 2016-01012019-A1. Special thanks to Plinio Gonzalez, Janina Seemann, and the staff of the Bocas del Toro Research Station for their help collecting fish and setting up the experiments. We also thank Kathleen Gilmour for access to laboratory space at the University of Ottawa. Funding was provided by a Smithsonian MarineGEO Postdoctoral Fellowship to E.S. and a Smithsonian STRI Fellowship to A.G. J.L.R. was supported by an Australian Research Council (ARC) Early Career Discovery Fellowship [PDE150101266] and infrastructure and research allocation from the ARC Centre of Excellence for Coral Reef Studies at James Cook University. S.J.C. was supported by the Natural Sciences and Engineering Research Council of Canada and the Canada Research Chairs Program. This is contribution 54 from the Smithsonian's MarineGEO Network.

\section{LITERATURE CITED}

Akamatsu T, Okumura T, Novarini N, Yan HY (2002) Empirical refinements applicable to the recording of fish sounds in small tanks. J Acoust Soc Am 112:3073-3082

Allsop DJ, West SA (2003) Constant relative age and size at sex change for sequentially hermaphroditic fish. J Evol Biol 16:921-929

* Andrew RK, Howe BM, Mercer JA (2011) Long-time trends in ship traffic noise for four sites off the North American west coast. J Acoust Soc Am 129:642-651

* Barton BA (2002) Stress in fishes: a diversity of responses with particular reference to changes in circulating corticosteroids. Integr Comp Biol 42:517-525

* Boyle KS, Cox TE (2009) Courtship and spawning sounds in bird wrasse Gomphosus varius and saddle wrasse Thalassoma duperrey. J Fish Biol 75:2670-2681

Celi M, Filiciotto F, Maricchiolo G, Genovese L and others (2016) Vessel noise pollution as a human threat to fish: assessment of the stress response in gilthead sea bream (Sparus aurata, Linnaeus 1758). Fish Physiol Biochem 42: 631-641

Codarin A, Wysocki LE, Ladich F, Picciulin M (2009) Effects of ambient and boat noise on hearing and communication in three fish species living in a marine protected area (Miramare, Italy). Mar Pollut Bull 58:1880-1887

Cox K, Brennan LP, Gerwing TG, Dudas SE, Juanes F (2018) Sound the alarm: a meta-analysis on the effect of aquatic noise on fish behavior and physiology. Glob Change Biol 24:3105-3116

* de Jesus EGT, Hirano T (1992) Changes in whole body concentrations of cortisol, thyroid hormones, and sex steroids during early development of the chum salmon, Oncorhynchus keta. Gen Comp Endocrinol 85:55-61

De Soto NA (2016) Peer-reviewed studies on the effects of anthropogenic noise on marine invertebrates: from scallop larvae to giant squid. In: Popper AN, Hawkins AD (eds) The effects of noise on aquatic life II. Springer, New York, NY, p 17-26

* Erbe C, Williams R, Sandilands D, Ashe E (2014) Identifying modeled ship noise hotspots for marine mammals of Canada's Pacific region. PLOS ONE 9:e89820

* Erbe C, Reichmuth C, Cunningham K, Lucke K, Dooling R (2016) Communication masking in marine mammals: a review and research strategy. Mar Pollut Bull 103:15-38

Erbe C, Marley SA, Schoeman RP, Smith JN, Trigg LE, Embling CB (2019) The effects of ship noise on marine mammals - a review. Front Mar Sci 6:606

Finneran JJ (2015) Noise-induced hearing loss in marine mammals: a review of temporary threshold shift studies from 1996 to 2015. J Acoust Soc Am 138:1702-1726

Frisk GV (2012) Noiseonomics: the relationship between ambient noise levels in the sea and global economic trends. Sci Rep 2:437

Froese R, Pauly D (2019) Halichoeres bivittatus. https:// www.fishbase.se/summary/Halichoeres-bivittatus.html (accessed 1 February 2020)

*Graham AL, Cooke SJ (2008) The effects of noise disturbance from various recreational boating activities common to inland waters on the cardiac physiology of a freshwater fish, the largemouth bass (Micropterus salmoides). Aquat Conserv 18:1315-1324

* Hatch L, Clark C, Merrick R, Van Parijs S and others (2008) Characterizing the relative contributions of large vessels to total ocean noise fields: a case study using the Gerry E. 
Studds Stellwagen Bank National Marine Sanctuary. Environ Manage 42:735-752

Hawkins AD, Popper AN (2017) A sound approach to assessing the impact of underwater noise on marine fishes and invertebrates. ICES J Mar Sci 74:635-651

Hildebrand JA (2009) Anthropogenic and natural sources of ambient noise in the ocean. Mar Ecol Prog Ser 395:5-20

Jain-Schlaepfer S, Fakan E, Rummer JL, Simpson SD, McCormick MI (2018) Impact of motorboats on fish embryos depends on engine type. Conserv Physiol 6: coy014

Jeffrey JD, Gilmour KM (2016) Programming of the hypothalamic-pituitary-interrenal axis by maternal social status in zebrafish (Danio rerio). J Exp Biol 219:1734-1743

Kaplan MB, Mooney TA (2015) Ambient noise and temporal patterns of boat activity in the US Virgin Islands National Park. Mar Pollut Bull 98:221-228

Kight CR, Swaddle JP (2011) How and why environmental noise impacts animals: an integrative, mechanistic review. Ecol Lett 14:1052-1061

Lawrence MJ, Jain-Schlaepfer S, Zoldero AJ, Algera DA, Gilmour KM, Gallagher AJ, Cooke SJ (2018) Are 3 minutes good enough for obtaining baseline physiological samples from teleost fish? Can J Zool 96:774-786

Maxwell RJ, Zolderdo AJ, de Bruijn R, Brownscombe JW, Staaterman E, Gallagher AJ, Cooke SJ (2018) Does motor noise from recreational boats alter parental care behaviour of a nesting freshwater fish? Aquat Conserv 28:969-978

Merchant ND, Pirotta E, Barton TR, Thompson PM (2014) Monitoring ship noise to assess the impact of coastal developments on marine mammals. Mar Pollut Bull 78: 85-95

Nedelec SL, Mills SC, Lecchini D, Nedelec B, Simpson SD, Radford AN (2016) Repeated exposure to noise increases tolerance in a coral reef fish. Environ Pollut 216:428-436

Nedelec SL, Radford AN, Pearl L, Nedelec B, McCormick MI, Meekan MG, Simpson SD (2017) Motorboat noise impacts parental behaviour and offspring survival in a reef fish. Proc R Soc B: Biol Sci 284:1856

Nichols TA, Anderson TW, Sirovic A (2015) Intermittent noise induces physiological stress in a coastal marine fish. PLOS ONE 10:e0139157

Normandeau Associates (2012) Effects of noise on fish, fisheries, and invertebrates in the US Atlantic and Arctic from energy industry sound-generating activities. US Department of the Interior, Bureau of Ocean Energy Management, Washington, DC

Parsons EC, Dolman SJ, Wright AJ, Rose NA, Burns WC (2008) Navy sonar and cetaceans: Just how much does the gun need to smoke before we act? Mar Pollut Bull 56: 1248-1257

Popper AN, Hastings MC (2009) The effects of anthropogenic sources of sound on fishes. J Fish Biol 75:455-489

Popper AN, Hawkins AD (2018) The importance of particle motion to fishes and invertebrates. J Acoust Soc Am 143: 470-488

Popper AN, Hawkins AD (2019) An overview of fish bioacoustics and the impacts of anthropogenic sounds on fishes. J Fish Biol 94:692-713

Pottinger TG, Carrick TR, Yeomans WE (2002) The threespined stickleback as an environmental sentinel: effects of stressors on whole-body physiological indices. J Fish Biol 61:207-229

Radford AN, Lebre L, Lecaillon G, Nedelec SL, Simpson
SD (2016) Repeated exposure reduces the response to impulsive noise in European seabass. Glob Change Biol 22:3349-3360

* Ramsay JM, Feist GW, Varga ZM, Westerfield M, Kent ML, Schreck CB (2006) Whole-body cortisol is an indicator of crowding stress in adult zebrafish, Danio rerio. Aquaculture 258:565-574

* Redfern JC, Cooke SJ, Lennox RJ, Nannini MA, Wahl DH, Gilmour KM (2017) Effects of maternal cortisol treatment on offspring size, responses to stress, and anxiety-related behavior in wild largemouth bass (Micropterus salmoides). Physiol Behav 180:15-24

* Robertson D, Ross D, Warner R (1978) Sexual patterns in the labroid fishes of the Western Caribbean, II, the parrotfishes (Scaridae). Smithson Contrib Zool 255:1-26

* Roul S, Kumar CRS, Das A (2019) Ambient noise estimation in territorial waters using AIS data. Appl Acoust 148: 375-380

Sarà G, Dean MJ, D'Amato D, Buscaino G and others (2007) Effect of boat noise on the behaviour of bluefin tuna Thunnus thynnus in the Mediterranean Sea. Mar Ecol Prog Ser 331:243-253

Scholik AR, Yan HY (2002) Effects of boat engine noise on the auditory sensitivity of the fathead minnow, Pimephales promelas. Environ Biol Fishes 63:203-209

Schwarz AL, Greer GL (1984) Responses of Pacific herring, Clupea harengus pallasi, to some underwater sounds. Can J Fish Aquat Sci 41:1183-1192

Simontacchi C, Negrato E, Pazzaglia M, Bertotto D, Poltronieri C, Radaelli G (2009) Whole-body concentrations of cortisol and sex steroids in white sturgeon (Acipenser transmontanus, Richardson 1836) during early development and stress response. Aquacult Int 17:7-14

Simpson SD, Radford AN, Nedelec SL, Ferrari MC, Chivers DP, McCormick MI, Meekan MG (2016) Anthropogenic noise increases fish mortality by predation. Nat Commun $7: 10544$

Slabbekoorn H, Bouton N, van Opzeeland I, Coers A, ten Cate C, Popper AN (2010) A noisy spring: the impact of globally rising underwater sound levels on fish. Trends Ecol Evol 25:419-427

* Smith ME, Kane AS, Popper AN (2004) Noise-induced stress response and hearing loss in goldfish (Carassius auratus). J Exp Biol 207:427-435

Kopinka NM, Hinch SG, Middleton CT, Hills JA, Patterson DA (2014) Mother knows best, even when stressed? Effects of maternal exposure to a stressor on offspring performance at different life stages in a wild semelparous fish. Oecologia 175:493-500

Sopinka NM, Donaldson MR, O'Connor CM, Suski CD, Cooke SJ (2016) Stress indicators in fish. In: Schreck CB, Tort L, Farrell AP, Brauner CJ (eds) Biology of stress in fish. Academic Press, Amsterdam, p 406-463

Staaterman E, Ogburn MB, Altieri AH, Brandl SJ and others (2017) Bioacoustic measurements complement visual biodiversity surveys: preliminary evidence from four shallow marine habitats. Mar Ecol Prog Ser 575:207-215

Staaterman E, Brandl SJ, Hauer M, Casey JM, Gallagher AJ, Rice AN (2018) Individual voices in a cluttered soundscape: acoustic ecology of the Bocon toadfish, Amphichthys cryptocentrus. Environ Biol Fishes 101:979-995

Stoot LJ, Cairns NA, Cull F, Taylor JJ and others (2014) Use of portable blood physiology point-of-care devices for basic and applied research on vertebrates: a review. Conserv Physiol 2:cou011 
Tavolga WN, Wodinsky J (1963) Auditory capacities in fishes: pure tone thresholds in nine species of marine teleosts. Bull Am Mus Nat Hist 126:179-239

Vabo R, Olsen K, Huse I (2002) The effect of vessel avoidance of wintering Norwegian spring spawning herring. Fish Res 58:59-77

Williams R, Wright AJ, Ashe E, Blight LK and others (2015) Impacts of anthropogenic noise on marine life: publication patterns, new discoveries, and future directions in research and management. Ocean Coast Manage 115: $17-24$
Wladichuk J, Hannay D, MacGillivray AO, Li Z (2018) Whale watching boats and small vessel underwater noise measurements study. Final report. Vancouver Fraser Point Authority ECHO program, Vancouver

Wright AJ, Aguilar Soto N, Baldwin NA, Bateson M and others (2007) Anthropogenic noise as a stressor in animals: a multidisciplinary perspective. Int J Comp Psychol 20: 250-273

Wysocki LE, Dittami JP, Ladich F (2006) Ship noise and cortisol secretion in European freshwater fishes. Biol Conserv 128:501-508

\section{Appendix.}

Table A1. Two-way ANCOVA to test the effects of experimental handling stress, collection site, and noise treatment on fish cortisol levels. Pairwise multiple comparison test results are shown. For each treatment pair, the difference in $y$-intercepts and corresponding p-values are reported. SPB: collected at STRI Point, baseline; SPC: collected at STRI Point, control treatment; SPN: collected at STRI Point, noisy treatment; HPB: collected at Hospital Point, baseline; HPC: collected at Hospital Point, control treatment; HPN: collected at Hospital Point, noisy treatment

\begin{tabular}{|lcc|}
\hline Comparison & Difference & p-value \\
\hline SPB vs. HPB & -0.1790 & 0.5228 \\
SPB vs. SPC & -0.6763 & 0.0000 \\
SPB vs. HPC & -0.6047 & 0.0000 \\
SPB vs. SPN & -0.6774 & 0.0000 \\
SPB vs. HPN & -1.0683 & 0.0000 \\
HPB vs. SPC & -0.4973 & 0.0004 \\
HPB vs. HPC & -0.4256 & 0.0045 \\
HPB vs. SPN & -0.4983 & 0.0003 \\
HPB vs. HPN & -0.8893 & 0.0000 \\
SPC vs. HPC & 0.0716 & 0.9914 \\
SPC vs. SPN & -0.0011 & 1.0000 \\
SPC vs. HPN & -0.3920 & 0.0193 \\
HPC vs. SPN & -0.0727 & 0.9903 \\
HPC vs. HPN & -0.4636 & 0.0019 \\
SPN vs. HPN & -0.3909 & 0.0157 \\
\hline
\end{tabular}

Editorial responsibility: Victor Benno Meyer-Rochow, Oulu, Finland

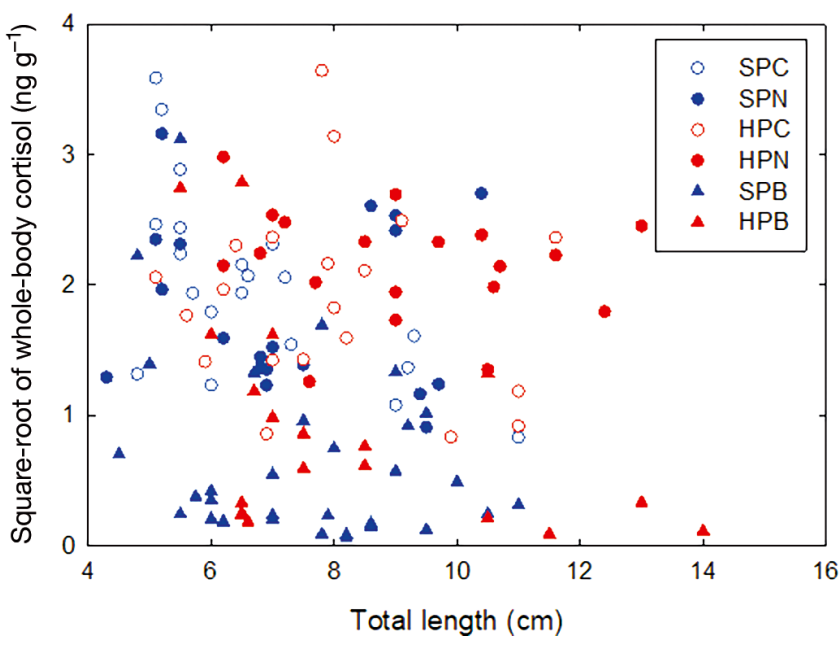

Fig. A1. Whole-body cortisol levels $\left(\mathrm{ng} \mathrm{g}^{-1}\right)$ and body length (cm) for Halichoeres bivittatus from STRI Point (blue) and Hospital Point (red) after in situ acoustic playback experiments. Treatment groups were STRI Point or Hospital Point 'control' (SPC and HPC), 'noise' (SPN and HPN), and baseline (SPB or HPB)

Submitted: November 1, 2019; Accepted: February 26, 2020 Proofs received from author(s): April 28, 2020 